\title{
Light as a feather: Effects of packaging imagery on sensory product impressions and brand evaluation
}

\author{
Thomas J. L. van Rompay • Marieke L. Fransen • \\ Bianca G. D. Borgelink
}

Published online: 15 August 2013

(C) Springer Science+Business Media New York 2013

\begin{abstract}
Inspired by the increasing importance of packaging design for product and brand management, this study tests effects of movement visuals and location of imagery on sensorial product impressions. Participants were exposed to a packaging variant for a fictitious brand of washing powder. Subsequently, they smelled packaging contents, estimated package weight, and evaluated product and brand. Findings show that movement visuals connoting upward (versus downward) movement resulted in the experience of a less concentrated smell, but only when presented in the top-left region of the package. Furthermore, imagery located in the top-left (versus bottom-right) region induced lower estimates of package weight. Additionally, findings show that location and movement visuals impact brand image formation and consumer preference.
\end{abstract}

Keywords Product packaging $\cdot$ Branding $\cdot$ Design $\cdot$ Embodiment $\cdot$ Product evaluation

\section{Introduction}

In today's market, consumer products are often similar in terms of quality and functioning, and more than ever, marketing communication strategies are needed to differentiate products from their competitors. Product and packaging design is a particularly promising means as it can, amongst others, elicit aesthetic delight (e.g.,

\section{T. J. L. van Rompay $(\bowtie)$}

Department of Industrial Design Engineering, University of Twente, P.O. Box 217, 7500 AE Enschede, The Netherlands

e-mail: t.j.l.vanrompay@utwente.nl

\section{L. Fransen}

Amsterdam School of Communication Research, University of Amsterdam, Amsterdam, The Netherlands

B. G. D. Borgelink

Department of Marketing Communication and Consumer Psychology, University of Twente, Enschede, The Netherlands 
Hine 1995; Honea and Horsky 2012), attract consumer attention in cluttered store environments (e.g., Schoormans and Robben 1997), and communicate symbolic product and brand qualities (Creusen and Schoormans 2005; Huettl and Gierl 2012; Van Rompay, De Vries, Bontekoe, and Tanja-Dijkstra 2012). Hence, when shopping for everyday products at the supermarket, consumers may base their purchase decisions on the product's visual appearance (Bloch 1995; Crilly, Moultrie, and Clarkson 2004), as when buying a "special design edition" bottle of mineral water (aesthetic delight), an eye-catching chocolate bar (consumer attention), or a "glamorous" shampoo bottle (symbolic meaning).

Consumers' reliance on visual appearances may also follow from a lack of relevant information (e.g., when buying a new brand of washing powder). Under these circumstances, product or packaging design may be a driver of consumer decisionmaking, because it allows consumers to draw inferences about the product's sensorial qualities (e.g., smell, taste, or volume perceptions) and may even modulate such basic sensorial impressions (Becker et al. 2011; Hoegg and Alba 2007). For instance, Becker et al. (2011) showed that product shape may influence taste experiences, with an angular (as opposed to a rounded) yoghurt packaging inspiring a more intense taste sensation.

It is precisely this appeal to (and influence on) consumers' most basic sensorial experiences that has generated considerable interest in effects that basic visual cues may sort. Hence, instead of relying on traditional tools of persuasion (e.g., slogans or product claims) through which meanings are imposed by advertisers, abstract visual cues rather induce consumer-generated attributions of brand meanings (Deng and Kahn 2009; Krishna 2012; Peracchio and Meyers-Levy 2005) that may also extend to other senses (e.g., Becker et al. 2011). In addition to global product features such as shape and color, research also points at the importance of visual-spatial parameters such as (vertical) size and location of imagery in advertisements and product packaging (Deng and Kahn 2009; Peracchio and Meyers-Levy 2005; Schubert 2005; Van Rompay et al. 2012). Of particular interest for current undertaking, Deng and Kahn (2009) showed that, depending on whether product images are placed on the top or bottom, packages appear lighter (top) or heavier (bottom).

This research extends previous research by testing effects of imagery location on sensory experience and introduces a previously unexplored visual factor (movement visuals). Specifically, we will test if and how movement and location visuals affect smell and volume perceptions for a fictitious brand of washing powder. Hence, does input provided by packaging visuals not only affect (cognitive) meaning attributions (as previous research attests to), but does it also affect subsequent sensorial product experiences? Before elaborating on the details of the study, first we will present a brief overview of relevant research.

\section{Movement and location in the perception of visual displays}

The notion that the suggestion of movement and location are important predictors of visual perception is widespread among artists and researchers interested in the visual arts (Arnheim 1969; Kandinsky 1926). Similarly, research shows that people across different cultures associate similar meanings with basic spatial orientations such as 
the "above" and "below" (Osgood 1960). The general line of reasoning accounting for such relationships holds that people entertain associations between location (i.e., "top" versus "bottom") and suggested movement (i.e., "upwards" versus "downwards") on the one hand, and specific affective qualities on the other (i.e., lightness versus heaviness connotations) because of our everyday embodied experiences (Dewey 1934; Johnson 1987; Lakoff and Johnson 1999; Schubert 2005). For instance, because we experience that going up takes effort, and all the more so with increasing load (e.g., climbing a mountain with heavy gear), we tend to associate heights with lightness or objects free from the forces of gravity, whereas the ground plane is readily associated with heaviness and people or objects that due to their weight are restricted to the horizontal dimension.

As such, this grounding of symbolic meanings in everyday embodied experiences explains why people associate locations in the upper regions of visual displays, or suggested movement towards these regions, with qualities that express lightness or emancipation (i.e., things of little weight more easily "defeat" the forces of gravity). Recently, Deng and Kahn (2009) showed that these principles also apply to the perception of product packaging. Specifically, they showed that product packaging appears more or less weighty dependent on whether imagery is presented in "light" (top, top-left) or "heavy" (bottom, bottom-right) locations.

Although to date no research in the consumer context has explored the impact of movement visuals, within the fields of perception and embodied cognition, accounts have been developed that are relevant to the present context (Barsalou 1999; Bundesen, Larsen, and Farrell 1983; Downing and Treisman 1997). Central to these accounts is the notion that observers (i.e., the visual system) "fill in" the trajectory suggested by dynamic stimuli and hence interpret visual patterns suggestive of movement in terms of the most likely (near-future) state of affairs (Downing and Treisman 1997).

A similar notion surfaces in "perceptual symbol systems" (Barsalou 1999) in which it is proposed that observers simulate (based on structural components of previous interactions stored in memory) interactions unfolding in the environment so as be able to plan, control, and execute subsequent actions called for. Both accounts acknowledge that the input for this "impletion" or "simulation" process may be incomplete, fragmented, or merely suggestive (e.g., the line-motion illusion; Downing and Treisman 1997). For the present context, this entails that a visual device suggestive of movement up(down)wards (i.e., an arrow in present research) instigates simulations in which consumers envision the end-state of the trajectory in either the upper (arrow pointing upwards) or lower (arrow pointing downwards) region of the package or beyond.

So far, however, research has not addressed the intriguing possibility that meanings connoted through both movement and location may also impact actual sensorial product experiences. Inspired by these findings, current research tests whether heaviness perceptions raised by movement and location visuals translate to related, managerially relevant sensorial experiences. Specifically, we will test whether a "heavy" (versus "light") visual impression enhances perceptions of product weight and whether it inspires the sensation of a "heavy-scented" smell.

In the context of cleaning products (the context of this study), both types of sensorial experiences are of managerial interest. That is, product weight and related 
volume perceptions are primary determinants of product value perceptions (Zeithaml 1988), and previous research likewise indicates that product smell (i.e., olfaction) is an important driver of consumer decision-making (Bone and Jantrania 1992; Fenko, Schifferstein, Huang, and Hekkert 2009). Specifically, smell perceptions may dominate consumer judgments with respect to care and cleaning products (Fenko et al. 2009). Of particular relevance to current undertaking, Fenko et al. (2009) assessed perceptions of product freshness in particular, a construct semantically related to the framing of lightness in current research as the extent to which consumers experience smell as "heavy-scented." Based on the foregoing, it is expected that:

H1 Suggested movement upwards (versus downwards) triggers perceptions of the product as less (versus more) weighty and less (versus more) heavy-scented.

H2 Presentation of product imagery in the top (versus bottom) region of a product package triggers perceptions of the product as less (versus more) weighty and less (versus more) heavy-scented.

And although effects of imagery location on product "lightness" impressions have been demonstrated previously, effects on brand personality perceptions have not been explored. The construction of brand personality is nowadays considered one of the key challenges in branding as it has been linked to, amongst others, brand equity, loyalty, trust, self-identity, and consumer preference (Aaker 1997). Thus, insights in couplings between impressions generated by visual stimuli and facets of brand personality are of managerial relevance. Of specific interest in this respect is the relationship between heaviness perceptions and brand activity (a central facet of brand perception; Geuens, Weijters, and De Wulf 2009).

Extending our embodied line of reasoning, a heavy visual impression should not only inspire impressions of a heavy product with a heavy scent but should also trigger perceptions of a static, inactive brand as heavy-weight objects require more force to change position and hence are readily perceived as static and inactive compared with light-weight objects that require little force to change position and therefore rather come across as active and spirited, impressions also tapped by Aaker's (1997) excitement facet (i.e., things that change and move are more likely perceived as exciting compared with motionless, inactive objects). Hence:

H3 Suggested movement upwards (versus downwards) makes a brand come across as more (versus less) active.

H4 Presentation of product imagery in the top (versus bottom) region of a product package makes a brand come across as more (versus less) active.

It is an open question to what extent location and movement interact. Perhaps, upward movement (i.e., rising against gravity) originating in the upper (versus lower) part of the package may contribute to a "lighter" impression as distance towards the outlines of the package is shorter and initiated movement is thus less likely to lose momentum before reaching the upper regions of the package. Reversely (following the same line of reasoning), perceptions of downward movement (and hence heaviness impressions) may be intensified when originating in the upper (versus lower) part (i.e., traversed trajectory is longer with movement gaining momentum).

Finally, we will also explore effects of location and movement (and their interactive effects) on more general consumer evaluations comprising packaging aesthetics 
and purchase intentions. Taking into consideration the associations of positive affect with "highs" (e.g., "I'm feeling up today") and negative affect with "lows" (e.g., "I'm so down") (Lakoff and Johnson 1999; Meier and Robinson 2004), overall positive effects of a "top location" and visuals connoting movement upwards are tentatively proposed.

To test these predictions and explorative research questions, different product packaging designs were constructed varying systematically in terms of location of product imagery and suggested movement and were subsequently presented to participants in order to record olfactory (i.e., smell of its contents), kinesthetic (i.e., perceived weight of the package), and visual (i.e., visual perception of the package) product impressions.

\section{Method}

\subsection{Pretest}

A pretest was conducted to ensure the effectiveness of the "suggested movement" manipulation. To this end, 16 participants (4 male, 12 female; mean age, 26.4 years) rated three pairs (each pair comprising an upward and downward variant) of movement stimuli (i.e., movement suggested by a gliding surface, arrow, or spiraling shape) on the item "this image connotes movement." Participants indicated (using seven-point rating scales ranging from "not at all" to "very much so") to what extent they considered this statement descriptive of these movement stimuli. Comparison of means showed that the "spiraling shape" variants reached the highest scores and, thus, most clearly connote movement. Specifically, for upward movement, the spiraling shape scored higher compared with the "gliding surface" $(M=5.38, S D=1.54$ versus $M=4.50, S D=1.83, p<0.05)$ and the "arrow" $(M=5.38, S D=1.54$ versus $M=3.94, S D=1.84, p<0.001)$. For downward movement, the spiraling shape likewise scored higher compared with the "gliding surface" $(M=4.94, S D=1.69$ versus $M=4.25, S D=1.84, p=0.08)$ and the "arrow" $(M=4.94, S D=1.69$ versus $M=3.69$, $S D=1.78, p<0.05)$.

Based on these results, the packaging variants for the main study were created. To this end, an existing package was redesigned with the selected movement variants (see Fig. 1 for examples of stimulus materials).

\subsection{Design and materials}

In line with previous research and common practice, these movement displays (i.e., packaging fronts comprising "upward," "downward," or "no movement" [control variant] visuals) were either placed in the top-left or bottom-right part of the washing powder package resulting in a 2 (location: "top-left" versus "bottom-right") $\times 3$ (movement: "upward movement" versus "downward movement" versus "no movement") between subject design.

In addition to the manipulations discussed, to enhance realism, all packaging variants featured a blue, cloudy sky, a slogan stressing product cleanliness and freshness, and additional product-specific logos (see Fig. 1). In order to assess weight 


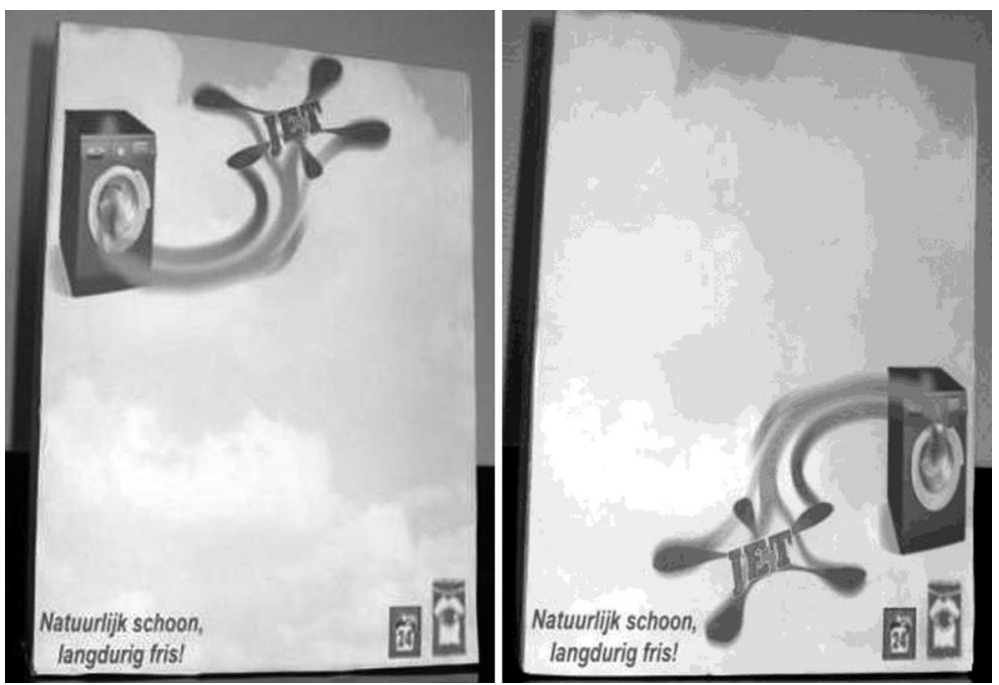

Fig. 1 Examples of stimulus materials

perceptions, no indications of product weight were provided on the package (actual package weight, 711 grams).

\subsection{Participants}

Participants $(N=144)$ were students at a university campus who participated in exchange for course credit and consumers (participating without incentive) intercepted upon leaving a medium-sized supermarket (33 male, 111 female; mean age, 31.0 years). All participants were naïve as to the purpose of the study and participated voluntarily.

\subsection{Procedure}

Participants were approached individually and asked to participate in an evaluation trial for a new (fictitious) brand of washing powder. After exposure to one of the packaging variants, participants filled out a questionnaire assessing brand and packaging evaluation. Subsequently, participants were explicitly instructed to pick up the package, smell its contents, and assess product weight. All packaging variants contained the same amount of an identical neutral-scented washing powder. After completion of the questionnaire, participants were thanked for their cooperation.

\subsection{Measures}

To measure sensorial impressions (smell and product weight), participants indicated to what extent they considered the product "heavy-scented" on a seven-point rating scale (ranging from "not at all" to "very much so"). Product weight impressions were recorded by having participants fill out the estimated number of grams. 
The extent to which the brand comes across as active was measured with the items dynamic, spirited, spontaneous, and young $(\alpha=0.87)$, items derived from Aaker's (1997) (conceptually related) brand excitement dimension and Geuens et al.'s (2009) brand activity dimension. Participants had to indicate to what extent they considered these items descriptive of the brand. Responses were recorded on seven-point rating scales ranging from "not at all" to "very much so."

Participants' aesthetic impression of the package was measured with the items appealing, attractive, and beautiful ( $\alpha=0.93)$. Using seven-point rating scales, participants had to indicate to what extent they considered these items descriptive of the package.

To measure purchase intent, participants indicated (using seven-point rating scales) to what extent they agreed with the statements "I would consider buying this product," "I would recommend this product to friends," and "I would like to try out this product" (alpha $=0.86$ ).

\section{Results}

Data were analyzed by performing a set of 2 (location: "top-left" versus "bottomright") $\times 3$ (movement: "upward movement" versus "no movement" versus "downward movement") full factorial ANOVAs.

\subsection{Smell impression}

Starting with product smell, the main effect of "Movement" was significant $(F(2,138)=3.24, p<0.05)$. Pairwise comparisons indicated that (in line with H1) the product was experienced as significantly more heavy-scented in the "downward movement" condition $(M=4.04, S D=1.35)$ compared with the "upward movement" $(M=3.38$, $S D=1.53)$ and "no movement" $(M=3.42, S D=1.47)$ conditions $(p ' s<0.05)$. The effect of "Location" did (contrary to H2) not reach significance $(F<1, \mathrm{~ns})$.

Furthermore, a significant "Location" by "Movement" interaction emerged $(F(2,138)=3.86, p<0.05$; see Fig. 2). Simple main effects analyses show that the three movement conditions do not differ in the "bottom-right" ("Location") condition $(F(2,138)=1.19, p=0.31)$, but that the difference between the movement variants is significant in the "top-left" ("Location") condition $(F(2,138)=5.94, p<0.01)$. Specifically, in the latter condition (see Fig. 2), the "downward movement" variant triggers an impression of the product as more heavy-scented compared with the "upward movement" variant $(M=4.29, S D=1.27$ versus $M=2.88, S D=1.26, p=0.001)$. The differences between the "downward movement" and "no movement" variant and between the "upward movement" and "no movement" variant were not significant ( $p=0.07$ and $p=0.12$, respectively). In sum, smell impressions triggered by the movement variants did only differ when imagery was placed in the top-left region of the product package.

\subsection{Weight perception}

The effect of "Movement" on estimated package weight was (contrary to H1) not significant $(F<1, \mathrm{~ns})$. The main effect of "Location" on estimated package weight was significant $(F(1,138)=8.73, p<0.01)$, indicating that (in line with H2) participants 


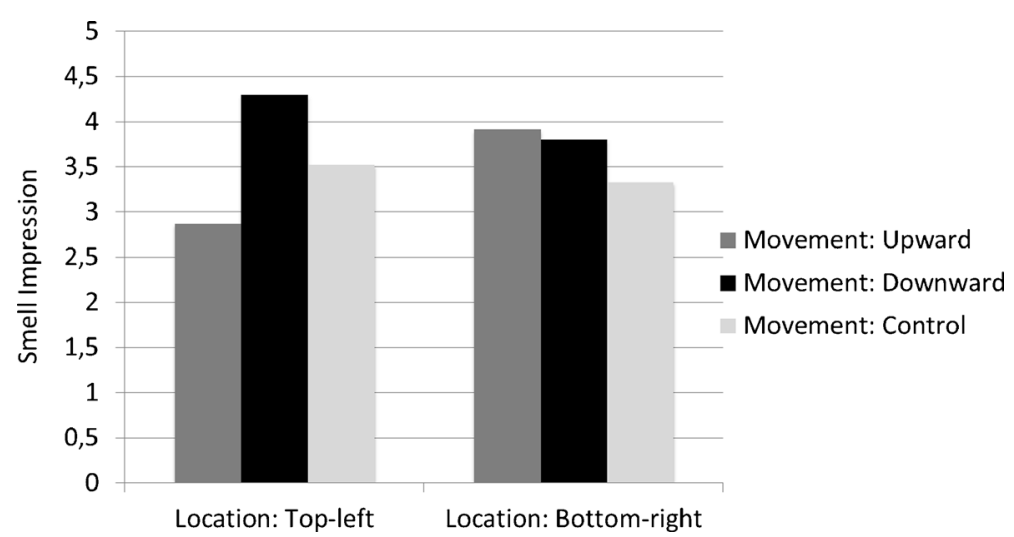

Fig. 2 Smell impression as a function of Location and Movement

considered the package heavier in the "bottom-right" $(M=853.77$ grams, $S D=428.21)$ compared with the "top-left" $(M=669.99$ grams, $S D=303.88)$ condition. The "Location" by "Movement" interaction was not significant $(F \mathrm{~s}<1, n s)$.

\subsection{Brand activity}

The main effect of "Movement" on perceptions of brand activity was (contrary to H3) not significant $(F(2,138)=1.56, p=0.21)$. The main effect of "Location" on brand activity was significant $(F(1,138)=4.00, p<0.05)$ indicating that (in line with H4) participants considered the brand as more active when imagery was presented in the top left $(M=4.25, S D=1.38)$ rather than the bottom-right $(M=3.51, S D=1.46)$ region of the package. The interaction between "Location" and "Movement" did not reach significance $(F<1, n s)$.

\subsection{Package evaluation}

The main effect of "Movement" on package evaluation was $\operatorname{significant}(F(2,138)=3.35$, $p<0.05)$. Pairwise comparisons showed that participants' ratings were higher when "upward" $(M=3.34, S D=1.75)$, compared with "downward" $(M=2.52, S D=1.31$, $p=0.03$ ) movement was connoted. The differences between the "upward movement" condition and the "no movement" condition and between the "downward movement" condition and the "no movement" condition were not significant ( $p=0.47$ and $p=0.74$, respectively). The main effect of "Location" on package evaluation was not significant, neither was the interaction between "Location" and "Movement" (both $F$ 's $<1, n s)$.

\subsection{Purchase intention}

Finally, the main effect of "Movement" on purchase intention was not significant $(F(2,138)=1.69, p=0.19)$. The main effect of "Location" on purchase intention was significant $(F(1,138)=12.47, p<0.01)$ indicating that purchase intentions were higher when imagery was presented in the top-left $(M=4.31, S D=1.34)$ rather than the bottom- 
right $(M=3.47, S D=1.47)$ region of the package. The interaction between "Location" and "Movement" did not reach significance $(F(2,138)=2.27, p=0.11)$.

\section{General discussion}

The findings presented partly confirm our predictions regarding effects of movement and location on sensorial impressions and product and brand evaluation. Building forth on previous research (Deng and Kahn 2009), our findings show that location of imagery impacts weight perceptions with imagery in the lower-right region of the package inspiring the sensation of a heavier package. In line with this effect, participants also considered the brand less active, which concurs with the embodied given that heavy objects are more static and less active (i.e., it takes more effort to change their position).

As for movement, however, our findings are less straightforward. First of all, no effects on perceptions of product weight were observed, perhaps suggesting that the manipulation was too subtle. That is, whereas the location manipulation involves an "end-state" or "destination" of imagery, the movement manipulation merely suggests an intended trajectory towards a specific destination. An alternative explanation holds that location of imagery is all-important with respect to weight perceptions (perhaps overshadowing effects of movement visuals) because heavy objects in particular are generally positioned on the ground. This may explain why imagery presented in the lower part of the package (corresponding to this experiential given) was so effective in triggering perceptions of a heavy package.

As for the movement manipulation, it was influential with respect to impressions of product smell. In line with hypotheses, upward movement triggered perceptions of the product as less heavy-scented (i.e., less concentrated) compared with downward movement. However, the interaction effect between location and movement showed that this effect only occurred when movement is presented in the upper (top-left) region of the package. Arguably, it is only in this condition (i.e., upward movement originating from the upper part of the package) that movement is perceived as extending beyond the confines of the package into the "open space" above (whereas upward movement originating in the lower part of the package is arguably more readily perceived as losing momentum upon reaching the upper regions of the package). As smells are commonly thought of as descending down on us from above, this might explain why an upward movement clearly transcending the vertical plane defined by the package had such a noteworthy impact.

In addition to the effects obtained on sensorial impressions and specific brand evaluations, of further interest are the effects of movement and location on participants' aesthetic impressions and purchase intentions respectively. In general, these findings concur with the notion that the vertical dimension and corresponding locations are generally associated with positive qualities or affective states (e.g., Meier and Robinson 2004). However, in the consumer context, qualities such as heaviness and stability may also be central to product and brand positioning as for instance in the case of foods with high nutrition value (Deng and Kahn 2009). In addition, care should be taken to ensure that different types of packaging elements (e.g., visuals and textual information) convey the same message such that consumers 
can easily process the information connoted and remember the brand (McCracken and Macklin 1998).

In terms of limitations, current research did not take the horizontal (right-left) dimension into account, a dimension that may likewise carry its own connotations (e.g., a person far ahead of his times or a person falling behind). Similarly, movement may be spiraling (as suggested by the movement visuals in current research), diffuse, concentrated, etc., and depending on such movement characteristics, associations may vary (e.g., concentrated movement arguably comes across as more confident or determined than diffuse movement).

More generally, it is of course true that product packaging comprises many more design elements besides the dimensions discussed in this paper, factors that may likewise impact sensorial impressions (e.g., color and shape; Becker et al. 2011) and volume perceptions (e.g., container height; Raghubir and Krishna 1999; Wansink and Van Ittersum 2003). Taking into account the widespread (cultural) concern with dieting, low-calorie foods, and corresponding light products, exploring such effects is certainly also interesting from a managerial point of view. However, care should be taken to ensure that the gap between expectations triggered by product packaging and subsequent product experience is not too large so as to backfire on product and brand evaluation (cf. Honea and Horsky 2012).

Finally, future research could also incorporate consumer characteristics such as design sensitivity or concern for visual aesthetics (Bloch, Brunel, and Arnold 2003) and consumer skepticism (Obermiller and Spangenberg 1998). With respect to advertising, for instance, skepticism has been shown to impact ad evaluations (e.g., Obermiller and Spangenberg 1998); however skepticism has not been studied in the context of product packaging. Considering the growing importance of health or "eco" concerns in society and corresponding growth of related claims and logos on product packaging, consumer weariness, skepticism or even cynicism (Chylinski and Chu 2010), and faith in truthfulness of packaging information may well be something to reckon with. As such, the importance of subtle visual elements that are not readily perceived as persuasive devices (forcing meanings into consumers' minds) should not be overlooked (cf. Krishna 2012). Awaiting future research addressing these and related issues, in the meantime, our findings attest to the feasibility of enhancing specific sensorial product impressions through packaging design.

\section{References}

Aaker, J. L. (1997). Dimensions of brand personality. Journal of Marketing Research, 34(3), 347-356. Arnheim, R. (1969). Visual thinking. Berkeley and Los Angeles: University of California Press.

Barsalou, L. W. (1999). Perceptual symbol systems. Behavioral and Brain Sciences, 22(4), 577-660.

Becker, L., Van Rompay, T. J. L., Schifferstein, H. N. J., \& Galetzka, M. (2011). Tough package, strong taste: The influence of packaging design on taste impressions and product evaluations. Food Quality and Preference, 22(1), 17-23.

Bloch, P. H. (1995). Seeking the ideal form: Product design and consumer response. Journal of Marketing, 59(3), 16-29.

Bloch, P. H., Brunel, F. H., \& Arnold, T. J. (2003). Individual differences in the centrality of visual product aesthetics: Concept and measurement. Journal of Consumer Research, 29, 551-565.

Bone, P. F., \& Jantrania, S. (1992). Olfaction as a cue for product quality. Marketing Letters, 3(3), $289-296$. 
Bundesen, C., Larsen, A., \& Farrell, J. E. (1983). Visual apparent movement: Transformations of size and orientation. Perception, 12, 549-558.

Chylinski, M., \& Chu, A. (2010). Consumer cynicism: Antecedents and consequences. European Journal of Marketing, 44(6), 796-837.

Creusen, M. E. H., \& Schoormans, J. P. L. (2005). The different roles of product appearance in consumer choice. Journal of Product Innovation Management, 22(1), 63-81.

Crilly, N., Moultrie, J., \& Clarkson, P. J. (2004). Seeing things: Consumer response to the visual domain in product design. Design Studies, 25(6), 547-577.

Deng, X., \& Kahn, B. E. (2009). Is your product on the right side? The "location effect" on perceived product heaviness and package evaluation. Journal of Marketing Research, 46(6), 725-738.

Dewey, J. (1934). Art as experience. New York: Berkley Publishing Group.

Downing, P., \& Treisman, A. (1997). The line-motion illusion: Attention or impletion? Journal of Experimental Psychology. Human Perception and Performance, 23(3), 768-779.

Fenko, A., Schifferstein, H. N. J., Huang, T., \& Hekkert, P. (2009). What makes products fresh: The smell or the colour? Food Quality and Preference, 20(5), 372-379.

Geuens, M., Weijters, B., \& De Wulf, K. (2009). A new measure of brand personality. International Journal of Research in Marketing, 26(2), 97-107.

Hine, T. (1995). The total packaging: The secret history and hidden meanings of boxes, bottles, cans and other persuasive containers. New York: Little Brown.

Hoegg, J., \& Alba, J. W. (2007). Taste perception: More than meets the eye. Journal of Consumer Research, 33(4), 490-498.

Honea, H., \& Horsky, S. (2012). The power of plain: Intensifying product experience with neutral aesthetic context. Marketing Letters, 23(1), 223-235.

Huettl, V., \& Gierl, H. (2012). Visual art in advertising: The effects of utilitarian vs. hedonic product positioning and price information. Marketing Letters, 23(3), 893-904.

Johnson, M. (1987). The body in the mind. Chicago: University Press Chicago.

Kandinsky, V. (1926). Point and line to plane. New York: Dover Publications Inc.

Krishna, A. (2012). An integrative review of sensory marketing: Engaging the senses to affect perception, judgment and behavior. Journal of Consumer Psychology, 22(3), 332-351.

Lakoff, G., \& Johnson, M. (1999). Philosophy in the flesh. New York: Basic Books.

McCracken, J. C., \& Macklin, M. C. (1998). The role of brand names and visual cues in enhancing memory for consumer packaged goods. Marketing Letters, 9(2), 209-226.

Meier, B. P., \& Robinson, M. D. (2004). Why the sunny side is up. Psychological Science, 15(4), $243-247$.

Obermiller, C., \& Spangenberg, E. R. (1998). Development of a scale to measure consumer skepticism toward advertising. Journal of Consumer Psychology, 7(2), 159-186.

Osgood, C. E. (1960). The cross-cultural generality of visual-verbal synesthetic tendencies. Behavioral Science, 5, 146-169.

Peracchio, L. A., \& Meyers-Levy, J. (2005). Using stylistic properties of ad pictures to communicate with consumers. Journal of Consumer Research, 32, 29-40.

Raghubir, P., \& Krishna, A. (1999). Vital dimensions in volume perception: Can the eye fool the stomach? Journal of Marketing Research, 36, 313-326.

Schoormans, J. P. L., \& Robben, H. S. J. (1997). The effect of new package design on product attention, categorization and evaluation. Journal of Economic Psychology, 18(2/3), 271-287.

Schubert, T. W. (2005). Your highness: Vertical positions as perceptual symbols of power. Journal of Personality and Social Psychology, 81(1), 1-21.

Van Rompay, T. J. L., De Vries, P. W., Bontekoe, F., \& Tanja-Dijkstra, K. (2012). Embodied product perception: Effects of verticality cues in advertising and packaging design on consumer impressions and price expectations. Psychology \& Marketing, 29(12), 919-928.

Wansink, B., \& Van Ittersum, K. (2003). Bottoms up! The influence of elongation on pouring and consumption volume. Journal of Consumer Research, 30, 455-463.

Zeithaml, V. A. (1988). Consumer perceptions of price, quality, and value: A means-end model and synthesis of evidence. Journal of Marketing, 52(3), 2-22. 